\title{
Treatment of Tendinopathy
}

\author{
What Works, What Does Not, and What is on the Horizon
}

\author{
Brett M. Andres MD, George A. C. Murrell MD, Dphil
}

Published online: 30 April 2008

(C) The Association of Bone and Joint Surgeons 2008

\begin{abstract}
Tendinopathy is a broad term encompassing painful conditions occurring in and around tendons in response to overuse. Recent basic science research suggests little or no inflammation is present in these conditions. Thus, traditional treatment modalities aimed at controlling inflammation such as corticosteroid injections and nonsteroidal antiinflammatory medications (NSAIDS) may not be the most effective options. We performed a systematic review of the literature to determine the best treatment options for tendinopathy. We evaluated the effectiveness of NSAIDS, corticosteroid injections, exercise-based physical therapy, physical therapy modalities, shock wave therapy, sclerotherapy, nitric oxide patches, surgery, growth factors, and stem cell treatment. NSAIDS and corticosteroids appear to provide pain relief in the short term, but their effectiveness in the long term has not been demonstrated. We identified inconsistent results with shock wave therapy and physical therapy modalities such as ultrasound, iontophoresis and low-level laser therapy. Current data support the use of eccentric strengthening protocols, sclerotherapy, and nitric oxide patches, but larger, multicenter trials are needed to confirm the early results with these
\end{abstract}

Each author certifies that he has no commercial associations (eg consultancies, stock ownership, equity interest, patent/licensing arrangements, etc) that might pose a conflict of interest in connection with the submitted article.

B. M. Andres ( $\square)$, G. A. C. Murrell Orthopaedic Research Institute, St George Hospital, University of New South Wales, Level 2 Research and Education Building, 4-10 South Street, Kogarah, Sydney, NSW 2217, Australia e-mail: bandres@yahoo.com treatments. Preliminary work with growth factors and stem cells is promising, but further study is required in these fields. Surgery remains the last option due to the morbidity and inconsistent outcomes. The ideal treatment for tendinopathy remains unclear.

Level of Evidence: Level II, systematic review. See the Guidelines for Authors for a complete description of levels of evidence.

\section{Introduction}

Traditionally, pain in and around tendons associated with activity has been termed tendonitis. This terminology implies the pain associated with these conditions results from an inflammatory process. Not surprisingly, treatment modalities have mainly been aimed at controlling this inflammation. The mainstays of treatment have included rest, nonsteroidal antiinflammatory medications (NSAIDs), and periodic local corticosteroid injections.

There are two problems with this approach. First, several studies demonstrate little or no inflammation is actually present in tendons exposed to overuse [83, 96, 163]. Second, traditional treatment modalities aimed at modulating inflammation have had limited success in treating chronic, painful conditions arising from overuse of tendons. More recently, the term tendinopathy has been advocated to describe the variety of painful conditions that develop in and around tendons in response to overuse. Histopathologic changes associated with tendinopathy include degeneration and disorganization of collagen fibers, increased cellularity, and minimal inflammation [83, 163]. Macroscopic changes include tendon thickening, loss of mechanical properties, and pain [163]. Recent work demonstrates several changes occur in response to overuse 
including the production of matrix metalloproteinases (MMPs), tendon cell apoptosis, chondroid metaplasia of the tendon, and expression of protective factors such as insulin-like growth factor 1 (IGF-1) and nitric oxide synthetase (NOS) [10, 76, 93, 99, 154, 155, 174, 199]. Although many of these biochemical changes are pathologic and result in tendon degeneration, others appear beneficial or protective. Tendinopathy appears to result from an imbalance between the protective/regenerative changes and the pathologic responses that result from tendon overuse. The net result is tendon degeneration, weakness, tearing, and pain.

As the basic science of tendinopathy has evolved, so have the treatment options for these conditions. We investigated the multitude of options proposed for the treatment of tendinopathy. Based on the authors' knowledge of the field and an extensive literature review, we evaluated the following treatment options: NSAIDS; exercise-based physical therapy; physical therapy modalities including iontophoresis, phonophoresis, ultrasound, transverse friction massage, and low-level laser therapy; corticosteroid injections; glyceryl trinitrate patches; shock wave therapy; sclerotherapy; surgery; growth factor treatment; and stem cell treatment. Our goal was to provide a comprehensive and up-to-date review of these treatment options with recommendations based on the best level of evidence available.

\section{Search Strategies and Criteria}

The available literature was reviewed using PubMed and the Cochrane register of controlled trials. An initial search of these databases using the terms "tendinopathy" OR "tendonitis" OR "tendinosis" OR "epicondylitis" resulted in 5745 and 408 hits, respectively. Limiting the search to English language clinical trials and meta-analyses resulted in 346 and 383 hits. The titles and abstracts of these articles were then individually reviewed. Only studies evaluating the treatment modalities described above were kept for this review. In addition, studies evaluating tendinopathy of the fingers and hand were discarded as tendinopathy seen in these tendons, which typically have synovial sheaths, appear to involve a different, often inflammatory process. Upon completion of this literature search, a total of 177 studies were selected for review. Based on the magnitude of this review, no attempt was made to grade these studies in terms of methodological quality. In the emerging treatment areas where few or no clinical trials have been performed, the literature search was expanded to include pilot studies and animal studies to better define the current and future options in these areas.

\section{FDA-approved NSAIDs}

Oral NSAIDs have been used extensively for decades to treat pain associated with tendon overuse. More recently, the local administration of NSAIDs through gels or patches has been advocated. Our literature search identified 37 randomized clinical trials and systematic reviews evaluating NSAIDS in the treatment of tendinopathy. Of these, only 17 studies were placebo-controlled $[2,13,30,48,58$, 61, 71, 89, 100, 105, 107, 133, 134, 148, 153, 164, 178]. Overall, the evidence suggests both oral and local NSAIDS are effective in relieving the pain associated with tendinopathy in the short term (7-14 days). Only three of the 17 studies evaluated showed no improvement with NSAIDS $[13,71,89]$. Oral and local NSAIDs appear effective in the treatment of acute shoulder bursitis/tendonitis [105, 107, 133, 134, 196]. One study also showed some success treating longer-standing shoulder pain with naprosyn sodium [133]. In a randomized, placebo-controlled, double-blind study, naprosyn sodium was more effective than placebo but not as effective as a corticosteroid injection in the treatment of shoulder bursitis/tendonitis at 4 weeks. Not surprisingly, the patients who presented with a longer duration and greater severity of symptoms were more likely to have a poor response to both corticosteroid injection and/or oral NSAIDs.

NSAIDs do not seem nearly as effective in treating lateral epicondylitis or Achilles tendinopathy [13, 64, 71, 106]. The only study to look at the effectiveness of NSAIDS for the treatment of lateral epicondylitis in the long term reported no difference between placebo and naproxen treatment groups at 1-year followup [71]. A systematic review of NSAID use for lateral epicondylitis identified data to support the use of local NSAIDs with a decrease in pain in the short term (2 weeks) [64]. However, there is little evidence to support or refute the use of topical or oral NSAIDs in the long term. In addition, long-term NSAID use increases the risk of gastrointestinal, cardiovascular, and renal complications associated with these medications. Overall, a short course of NSAIDs appears a reasonable option for the treatment of acute pain associated with tendon overuse, particularly about the shoulder. There is no clear evidence that NSAIDS are effective in the treatment of chronic tendinopathy in the long term.

\section{Physical Therapy}

Physical therapy has been commonly used for the treatment of tendinopathies. There is, however, mixed data to support its use. The type of therapy used can be quite variable from one therapist to the next, and orthopaedic surgeons are often not involved in choosing the type of therapy used. 
Stretching and strengthening programs are a common component of most therapy programs. Therapists also use other modalities, including ultrasound, iontophoresis, deep transverse friction massage, low-level laser therapy, and hyperthermia.

\section{Stretching/Strengthening}

Eccentric strengthening programs have recently been advocated in the treatment of tendinopathy (Fig. 1A-C) [7, 103, 158]. Our literature review identified 16 controlled clinical trials and systematic reviews evaluating this modality. One of these studies had a control group that received no treatment [143]. This study showed improvement in the eccentric strengthening group compared to a "wait and see" group at 4 months. The other clinical trials evaluating eccentric strengthening compared it to other treatment modalities $[14,56,78,103,104,117,132,141$, 145, 190]. A 12-week course of eccentric strengthening exercises was more effective than a traditional concentric strengthening program for treating Achilles and patellar tendinopathy in recreational athletes $[78,103]$. In the Achilles tendinopathy study, $82 \%$ of the patients randomized to the eccentric strengthening protocol described improvement in pain levels compared with $36 \%$ in the concentric training group. Imaging of the Achilles tendon before and after a 12-week eccentric training protocol showed thinning and normalization of the tendon structure both on ultrasound and MRI [120, 157]. Interestingly, eccentric strengthening produced better results in tendinopathy of the midsubstance of the Achilles compared with insertional tendinopathy [53].

Eccentric strengthening protocols have also been successful in the treatment of lateral epicondylitis [41]. In a well-designed study, 92 patients with lateral epicondylitis were randomized to a standard physical therapy protocol with and without an eccentric strengthening program [41]. The group with the eccentric strengthening showed a considerable improvement in pain, strength, and function compared with the control group. A similar study showed no difference among patients assigned to stretching and icing alone, stretching and icing with eccentric strengthening, or stretching and icing with concentric strengthening [104]. A systematic review of the literature on eccentric strength training for the treatment of tendinopathy has been published [197]. Based on the variable results of the current studies, this review concluded there is only limited evidence to support the use of eccentric exercise over other treatments such as concentric exercise, stretching, splinting, massage, and ultrasound.

In addition to the data on eccentric strengthening, good results have been reported with a formal mobilization and
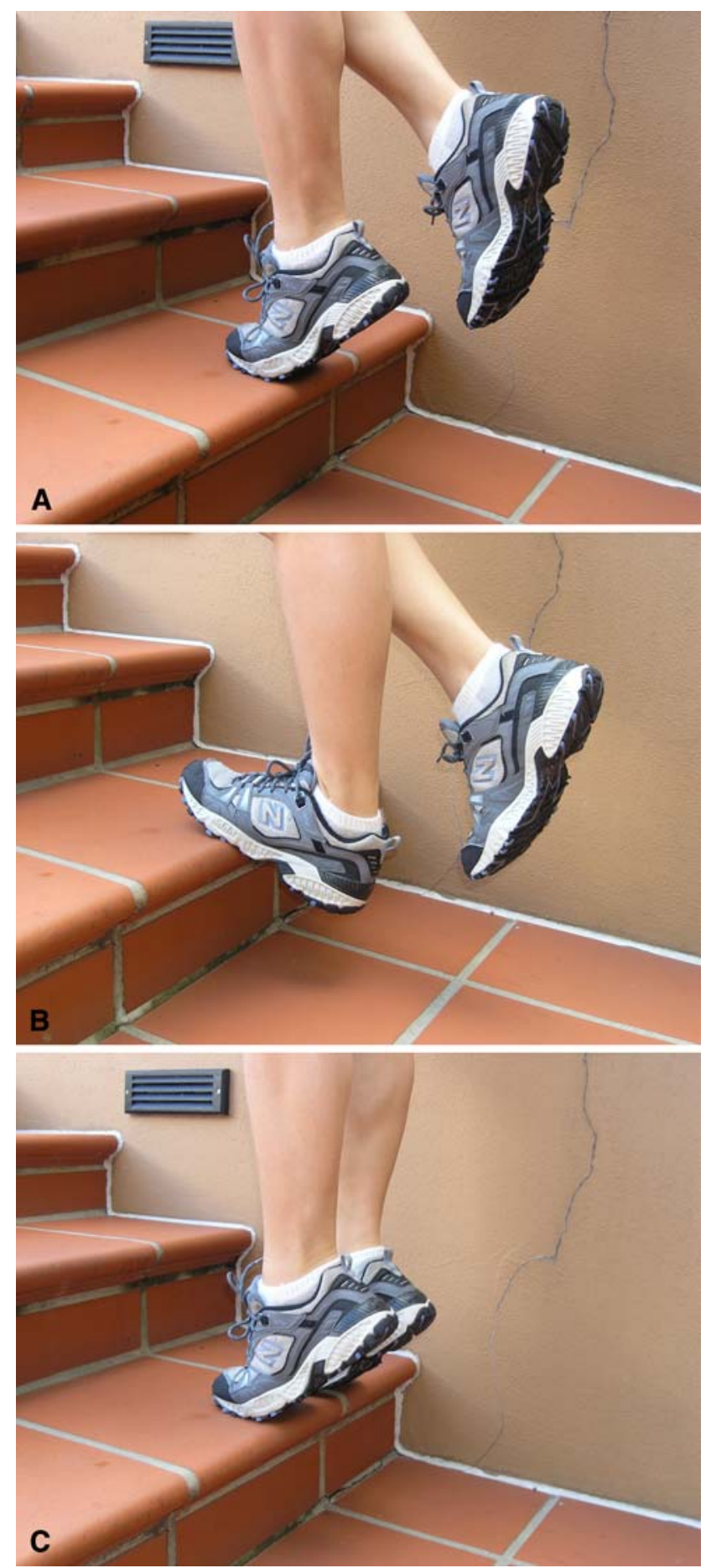

Fig. 1A-C An eccentric training protocol for the treatment of Achilles tendinopathy is demonstrated. (A) The patient starts in a single-leg standing position with the weight on the forefoot and the ankle in full plantar flexion. (B) The Achilles is then eccentrically loaded by slowly lowering the heel to a dorsiflexed position. (C) The patient then returns to the starting position using the arms or contralateral leg for assistance to avoid concentric loading of the involved Achilles tendon.

strengthening program for rotator cuff tendonitis [15, 27, 37]. In one study, 125 patients were randomized to arthroscopic acromioplasty, a formal supervised rotator 
cuff strengthening program, or a placebo laser treatment [27]. Both the acromioplasty group and the physical therapy group had improved pain scores at 6 months compared with the placebo group. There was no difference in pain scores between the two treatment groups. In another randomized clinical trial, 52 patients with shoulder impingement were assigned to manual physical therapy in addition to a stretching and strengthening protocol or to stretching and strengthening without manual therapy [15]. The study reported the addition of manual therapy resulted in an improvement in pain scores and strength at followup.

\section{Other Modalities}

There are a wide variety of modalities available to the physical therapist, and it is difficult to predict which technique or group of techniques a given therapist will utilize. While a typical orthopaedic surgeon is not involved in prescribing these treatments, it is worthwhile to have a feeling for what treatment options are available and how effective they are. Ultrasound, iontophoresis, low-level lasers, and phonophoresis are FDA approved; the 434-MHz hyperthermia device is not FDA approved for tendinopathy.

Our literature review identified 51 references for clinical trials and systematic reviews of common therapy modalities. Low-level laser treatment (LLLT) has been studied extensively with mixed results. Of the 14 randomized clinical trials evaluating LLLT, two were discarded due to inadequate controls. Of the remaining studies, five showed improvement treating tendinopathy with LLLT compared to placebo LLLT [23, 52, 90, 170, 171], while seven studies showed no difference $[16,21,69,87,101,184$, 186]. Four systematic reviews have addressed LLLT and all agreed the best current level of evidence does not support its use in the treatment of tendinopathy $[65,106$, $168,181]$.

The other physical therapy modalities have not been studied as extensively, but have similar conflicting results in the literature. Iontophoresis and phonophoresis involve using ionizing current or ultrasound to deliver medications locally. Corticosteroids and NSAIDS are commonly used with these modalities. Only six adequately controlled studies could be identified and four of these reported no improvement compared to controls [84, 116, 147, 185]. Transverse friction massage has also been used to treat tendinopathy, but only three studies have evaluated this modality [26, 51, 167]. None of these studies showed a benefit to deep friction massage over other physical therapy modalities. A Cochrane review evaluating deep friction massage found no benefit with deep friction massage over other treatments.
Another physical therapy modality commonly used in the treatment of tendinopathy is therapeutic ultrasound. Eight well-controlled trials and systematic reviews were identified on this subject [20, 42, 47, 49, 84, 137, 167, 183]. Three controlled trials demonstrated a benefit [20, 49, 84] with therapeutic ultrasound used in the treatment of lateral epicondylitis and calcific tendonitis of the supraspinatus. A systematic review of physical therapy modalities used for the treatment of shoulder pain suggested ultrasound appeared effective for the treatment of calcific tendonitis [1]. Another extensive systematic review of the medical and physical therapy literature investigated the use of ultrasound for the treatment of musculoskeletal disorders [183]. The only area where ultrasound showed slight promise was in the treatment of lateral epicondylitis. Pooled data from trials evaluating the treatment of lateral epicondylitis with ultrasound compared to controls showed the estimated difference in success rate to be $15 \%$.

Hyperthermia has also been used in the treatment of tendinopathy. This modality involves using deep-heating machines that combine a superficial cooling system with a microwave-powered heating system. This can increase the temperature of target tissues approximately $4^{\circ} \mathrm{C}$ without damaging the skin. Presumably this increased temperature results in increased blood flow and subsequent healing to the damaged area. Two randomized clinical trials from a single institution have been published evaluating hyperthermia compared to therapeutic ultrasound in the treatment of tendinopathy [62, 63]. These trials report improvements in pain and patient satisfaction in the hyperthermia group compared to the ultrasound group. No other clinical trials have evaluated hyperthermia in the treatment of tendinopathy.

In summary, there is some evidence that eccentric strengthening programs may be effective in the treatment of tendinopathy. There is currently little evidence available to support the use of most physical therapy modalities including LLLT, iontophoresis, phonophoresis, therapeutic ultrasound, or deep friction massage. One exception to this is the use of ultrasound for calcific tendonitis. Early data on hyperthermia is also encouraging, but remains preliminary. Further research with higher-powered studies would be useful to determine the most effective physical therapy regime for the treatment of tendinopathies.

\section{FDA-approved Corticosteroids}

Corticosteroid injections have been a mainstay in the treatment of tendinopathy. Despite their widespread use, there is some controversy as to their usefulness and safety in this setting. Our literature search identified 19 controlled trials and systematic reviews with mixed results regarding 
corticosteroid injections in the treatment of tendinopathy $[2,8,9,11,12,43,71,73,86,114,133,149,159,160,172$, 180, 187, 193, 194]. Several studies report good short-term pain control ( $\leq 6$ weeks) with corticosteroid injections in patients with lateral epicondylitis and shoulder impingement [46, 71, 160, 188]. The long-term efficacy of corticosteroid injections for tendinopathy has not been demonstrated. Corticosteroid injections for lateral epicondylitis do not provide any long-term benefit (6-12 months) compared with placebo, NSAIDs, or physical therapy in randomized, controlled studies [71, 159, 160, 188]. Mixed results have been published with regard to the long-term benefits of subacromial corticosteroid injections for rotator cuff tendinopathy. Several well-controlled studies report a small but statistically significant level of improvement in the short term using corticosteroids in the treatment of shoulder impingement [3, 25, 133]. In contrast, several authors have reported no major benefit with corticosteroid injections over control patients in the treatment of shoulder impingement [9, 187]. An extensive systematic review evaluating the efficacy of corticosteroid injections in the treatment of rotator cuff disease recently reported little or no evidence to support the use of corticosteroid injections for these patients [86].

In addition to the question of the efficacy of corticosteroid injections in the medium-term treatment of tendinopathy, there is a question of safety with using these medications in this setting. Several cases of Achilles tendon rupture have been reported after corticosteroid injections to this region [17, 32, 55, 77, 85]. More recently, Gill et al. [60] described a series of 83 injections to the Achilles region without serious complication. The key point here is they injected the steroid under fluoroscopic guidance around the tendon but not within the substance of the tendon. Of note, only $40 \%$ of the patients in this series reported improvement after the procedure at the 2-year followup.

In summary, corticosteroid injections have been used for decades in the treatment of tendinopathy. There is strong evidence they relieve pain in the short term up to 6 weeks, but there is no evidence they provide any benefit in the long term (beyond 6 months) for the treatment of chronic tendinopathy. It appears the risks associated with corticosteroid injections can be minimized by injecting under image guidance to ensure the injection is paratendinous rather than intratendinous.

\section{Glyceryl Trinitrate Patches}

The treatment of tendinopathy with glyceryl trinitrate patches is an off-label use of an FDA-approved medication. Nitric oxide (NO) is a soluble molecule produced by a family of enzymes called nitric oxide synthases (NOS). In large doses, NO can be toxic, but in smaller, physiological doses, it acts as a cellular messenger and appears to play a role in blood pressure, memory, and host defense. NO appears to play a role in tendon healing after injury. In a rat Achilles tendon healing model, inhibition of NOS resulted in a decreased cross-sectional area and load to failure of the healing tendon [112]. The addition of NO in this model enhances tendon healing suggesting the addition of exogenous NO to an area of tendon damage may promote tendon healing [198].

Based on this information, three randomized, controlled, double-blind clinical studies were designed to determine whether the topical administration of NO would enhance tendon healing in humans. In these studies, NO was delivered transcutaneously to the area of painful tendinopathy using commercially available glyceryl trinitrate (GTN) patches (Fig. 2A-B). This series of trials evaluated the effectiveness of the GTN patch in the treatment of lateral epicondylitis, Achilles tendinopathy, and rotator cuff tendinopathy [124-126]. In all three studies, 53 to 86

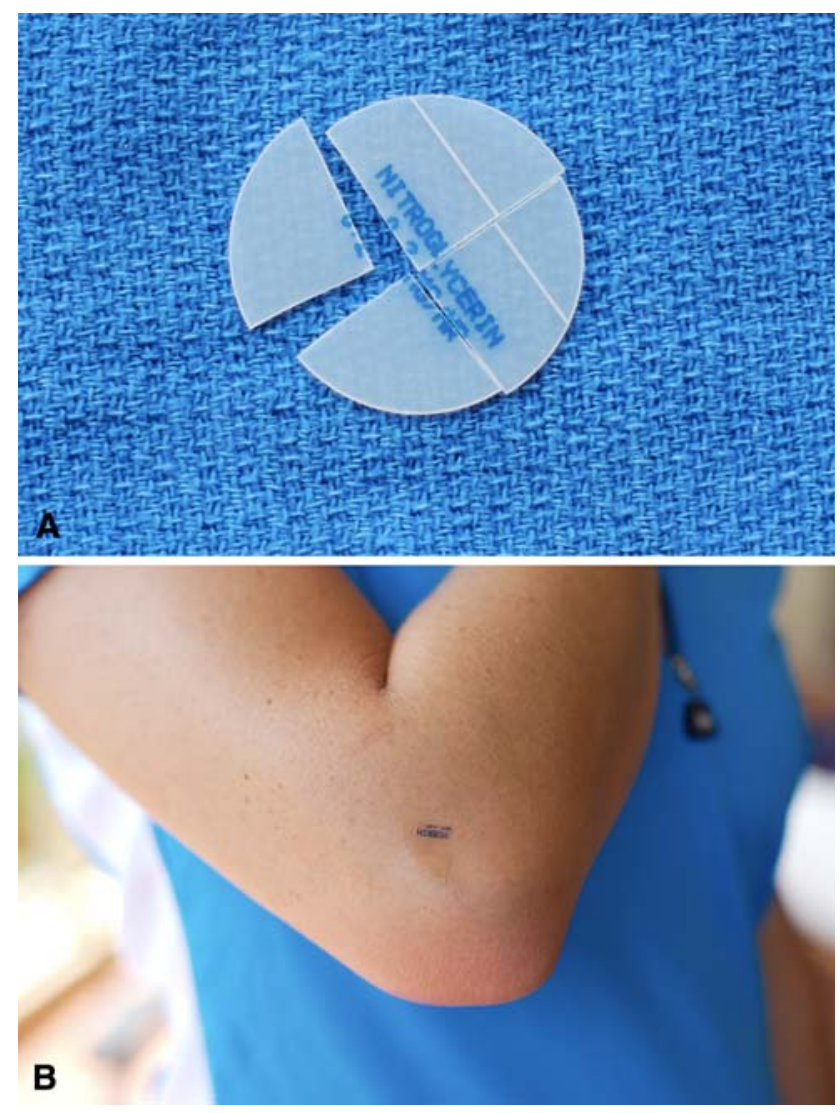

Fig. 2A-B (A) A 5-mg/24-hour glyceryl trinitrate patch is cut into quarters and (B) placed over the area of maximal tenderness/pain as shown in a patient with lateral epicondylitis. The patch is left in place for 24 hours and then replaced with a new quarter patch. 
patients were randomly assigned to the treatment group or control group. The treatment group received GTN patches that delivered $1.25 \mathrm{mg}$ GTN every 24 hours. The control group received a placebo patch. The patients and investigators were blinded to which patch was given to the patient. Both groups of patients were instructed to place the patch directly over the area of greatest tenderness/pain and to change the patch every 24 hours. The patches were worn until the symptoms subsided or the study ended (6 months).

All three studies showed improvement in the treatment groups compared with the control groups. In addition to decreased pain, patients demonstrated increased power and improved function in the area of interest. Most impressive was the percentage of patients who were asymptomatic with activities of daily living in the treatment group compared with the control group. In the tennis elbow study, $81 \%$ of the treatment group was asymptomatic compared with $60 \%$ of the control group. The Achilles tendinopathy study showed $78 \%$ of the treatment group asymptomatic with activities of daily living at 6 months versus $49 \%$ of the control group. Lastly, the supraspinatus tendinopathy data showed $46 \%$ of patients asymptomatic in the treatment group compared with $24 \%$ of the control subjects.

There is some question whether nitric oxide simply has an analgesic effect or a healing effect in the treatment of tendinopathy. A 3-year followup of the Achilles tendinopathy study described above has recently been published [127]. It showed persistent improvement in the group treated with the GTN patches for 6 months compared to the control group. At 3 years, $88 \%$ of the treatment group was completely asymptomatic compared to $67 \%$ of the control group. This study suggests treatment with transdermal GTN had a healing effect rather than an analgesic effect in Achilles tendinopathy. In contrast to this, another randomized clinical trial was previously published comparing a 3-day course of transdermal nitroglycerin patches to placebo in 20 patients with rotator cuff tendinopathy [19]. This study reported an improvement in pain scores in the treatment group compared to the control group as early as 24 hours after starting the patch. The improvement in pain was seen at all three time points: 1, 2, and 15 days. This suggests topical nitric oxide may have an analgesic effect as well.

As a whole, these studies provide convincing evidence the administration of NO directly over an area of tendinopathy through a GTN patch enhances healing and provides some pain relief in the treatment of tendinopathy. The most commonly described side effect seen with this treatment modality is headaches [19, 124-127]. The headaches can be severe enough to cause cessation of treatment. As the majority of the work in the area of NO in the treatment of tendinopathy has come from one group, larger multicenter trials would be useful in validating this treatment modality.

\section{Extracorporeal Shock Wave Therapy}

Extracorporeal shock wave therapy (ESWT) has been advocated for treating a number of soft tissue conditions, including plantar fasciitis, lateral epicondylitis, calcific and noncalcific tendonitis of the supraspinatus, and tendinopathy of the Achilles tendon. It is FDA-approved for plantar fasciitis and lateral epicondylitis only. ESWT entails delivering a series of low-energy shock waves directly over the painful area of the tendon. The mechanism by which ESWT would provide pain relief or enhance tendon healing is not clear. Ohtori et al. [121] reported the administration of a single session of low-energy shock waves to rat skin resulted in nearly complete degeneration of epidermal sensory nerve fibers. The fibers began to regenerate in 14 days. By applying a second session of shock waves at 14 days, the nerve fiber regeneration was delayed to 42 days [175]. There is also evidence tenocytes release growth factors in response to ESWT that may promote tendon healing. Chen et al. [33] reported administering shock waves to a rat Achilles tendinopathy model resulted in increased tenocyte proliferation and increased expression of transforming growth factor-betal and insulin growth factor 1 .

The ideal method for applying ESWT is also not clear. Published trials vary greatly with regard to the intensity and frequency of the shock waves, the duration of the treatment, the timing and number of repeat treatments given, and the use of local anesthetic. This variability makes it difficult to compare one study with the next.

The most important question about ESWT is whether it is effective in treating tendinopathy. This treatment modality has been extensively studied over the past 10 years, and there is a great deal of variability in the data. Our literature search identified 34 clinical trials and systematic reviews investigating ESWT. The most convincing data are seen in the treatment of calcific tendonitis of the supraspinatus. Several large randomized, controlled trials report good results using ESWT in the treatment of calcific tendonitis of the rotator cuff with a reported improvement in pain scores and a decrease in the size of calcific deposits seen on radiographs compared with placebo [4, 31, 39, 59, $98,110,123,130,131,136,140]$. One advantage to treating calcific tendonitis with this method is the ability to visualize the area of pathology and target this area with the shock waves [67, 74, 150]. Improved efficacy has been demonstrated when using computer-guided navigation when applying shock waves to calcific tendonitis [150]. The effectiveness of ESWT for treating noncalcific 
tendonitis has been less promising. Two controlled, randomized clinical trials report no major benefit with ESWT compared with placebo for the treatment of noncalcific tendinopathy of the supraspinatus $[152,166]$.

Variable results have been demonstrated with the use of ESWT in the treatment of lateral epicondylitis. There have been reports of improved pain and function compared to control groups using ESWT in the treatment of lateral epicondylitis $[135,142]$. However, the majority of studies evaluating ESWT for the treatment of lateral epicondylitis report no improvement using this modality compared to controls [35, 68, 91, 165]. Two systematic reviews have investigated this issue and have concluded ESWT provides little or no benefit in the treatment of lateral epicondylitis $[22,29]$. Similar, contradictory findings are seen with the use of ESWT in the treatment of Achilles tendinopathy. One study reported ESWT comparable to eccentric training and superior to a wait-and-see policy for the treatment of Achilles tendinopathy in a randomized clinical trial [143]. In contrast, another randomized, double-blind clinical trial reported no difference between patients treated with ESWT and sham ESWT in the treatment of Achilles tendinopathy [40]. Of note, this study also reported two episodes of Achilles tendon rupture in the ESWT group and questioned the safety of this treatment modality for the Achilles tendon in older patients.

In summary, ESWT remains a controversial treatment option for tendinopathy. Good evidence is available to support the use of this modality in calcific tendinopathy of the rotator cuff. The best current evidence does not support its use in noncalcifying tendinopathy of the rotator cuff or lateral epicondylitis. Further evidence is needed to justify the use of ESWT in Achilles tendinopathy and patellar tendinopathy. It is difficult to make conclusions with the current data available because of the wide variability in results and treatment protocols between studies.

\section{Sclerotherapy}

Sclerotherapy involves injecting a chemical into a blood vessel, which results in sclerosis of that vessel. Polidocanol was used as the sclerosing agent in all of the studies. Polidocanol is not FDA-approved although other sclerosing agents are. The rationale behind using sclerotherapy in tendinopathy is based on the finding that there is a proliferation of small blood vessels in areas of tendinopathy. Nerve fibers appear to travel in close proximity to these areas of neovascularization [24, 95, 97]. It is possible these nerve fibers are the pain generators in tendinopathy. In theory, injecting a sclerosing agent into the areas of neovascularization could not only sclerose the vessels, but also may eradicate the pain-generating nerve fibers. These injections are performed under Doppler ultrasound guidance (Fig. 3A-C).

This theory has been tested in a series of clinical trials evaluating the treatment of tennis elbow, patellar
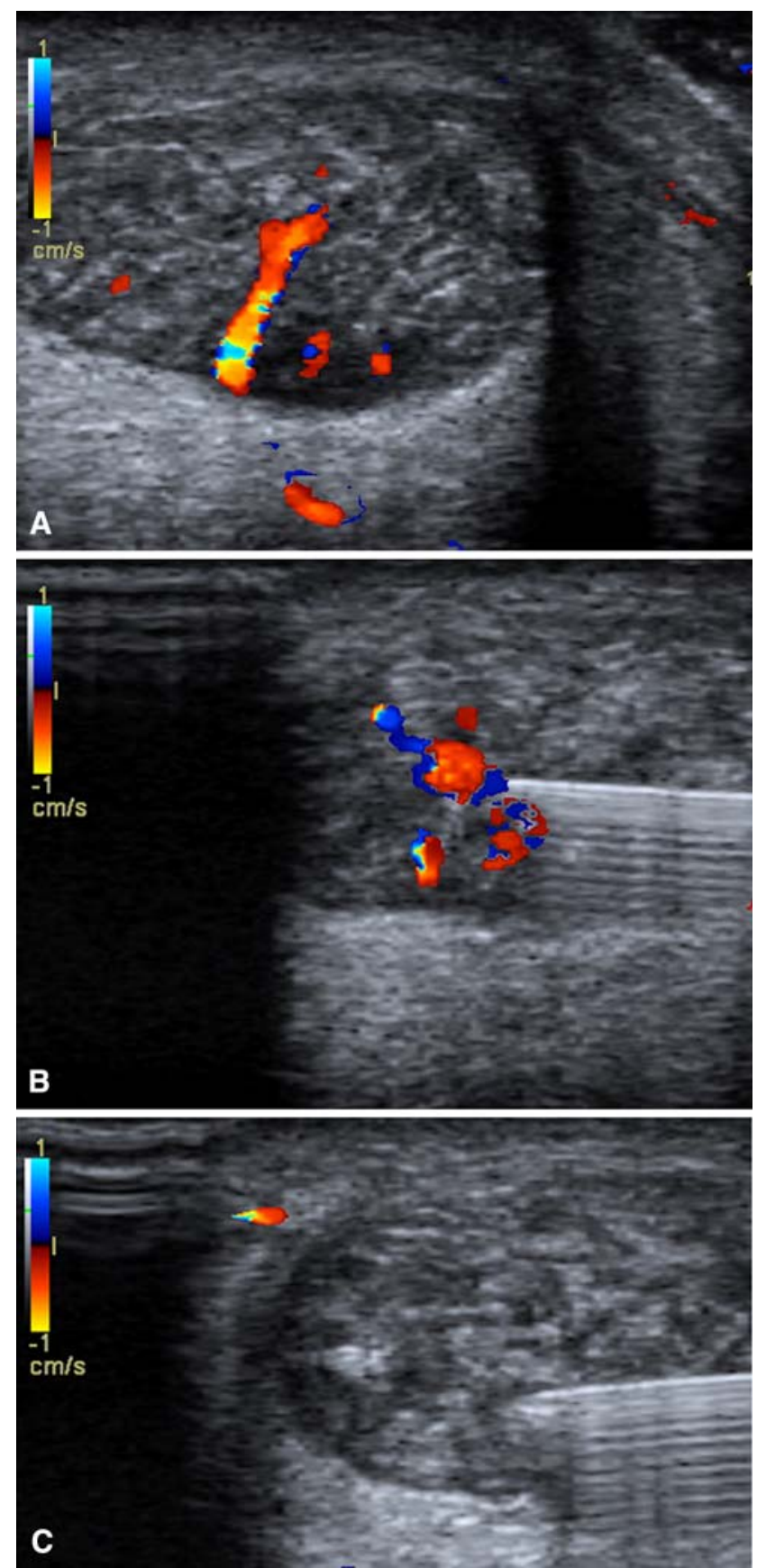

Fig. 3A-C Injection of a sclerosing agent is shown using Doppler ultrasound for guidance. (A) The presence of neovessels is detected in the Achilles tendon using color Doppler ultrasound before injection. (B) A 23-gauge needle is passed into the area of neovascularization under ultrasound guidance and the sclerosant is injected. (C) Ablation of blood flow within the neovessels is demonstrated after injection of the sclerosing agent. 
tendinopathy, and Achilles tendinopathy with sclerotherapy $[72,119,200]$. High-resolution ultrasonography with color Doppler was performed in all studies to locate areas of neovascularization and to guide injection of the sclerosing agent, polidocanol. This treatment method showed promising results in two small pilot studies $[119,200]$. In the first study, polidocanol was injected in 13 elbows with lateral epicondylitis. A good short-term (8 months) result with increased strength and decreased pain was seen in 11 of 13 elbows [200]. Similar results were seen in a pilot study injecting the midsubstance of the Achilles tendon with the sclerosing agent. Here a good result was reported in eight of 10 Achilles tendons at 6 months followup [119]. This report was followed by a larger series of 42 patients treated with polidocanol injections for midsubstance Achilles tendinopathy. At 2 years followup, 38 of 42 patients were satisfied with their results and showed a considerable decrease in mean pain visual analog scale scores from 75 before the procedure to 7 at the latest followup [94]. Similar results were reported in a small randomized, controlled trial in which 20 patients with Achilles tendinopathy were randomly assigned to treatment with polidocanol or lidocaine injections [6]. The treatment group reported better pain relief at 3 months. Recently, a double-blind, randomized, controlled trial comparing polidocanol injections with lidocaine injections for the treatment of patellar tendinopathy was published [72]. Thirty-seven patients with patellar tendinopathy and confirmed neovascularization within the patellar tendon were randomly assigned to a treatment or control group. At the 4-month followup, the treatment group showed improvement compared with the placebo group. At this point, the control group was crossed over to the treatment side of the study and received polidocanol injections. At 8- and 12month followup, the treatment and control groups showed improvement in pain and function compared with their pretreatment scores.

Although polidocanol injections appear to provide pain relief, it is unclear what role they may play in tendon healing in tendinopathy. Intuitively, one would think sclerosing the neovessels of a damaged tendon would be detrimental to tendon healing and could possibly even cause more damage. Polidocanol injections do appear safe, however. Alfredson and Cook have reported only two complications possibly related to the treatment after injecting over 400 Achilles lesions [5]. These include one complete Achilles rupture and one partial rupture.

Ablation of neovascularization with sclerosing agents is a promising option in the treatment of tendinopathy. Essentially all of the data published in this area to date have come from the group that originally described the technique. Further data from other investigators or a multicenter study would be extremely valuable in validating the safety and efficacy of this technique.

\section{Surgery}

Surgery is often considered a last option in the treatment of tendinopathy that persists after exhausting all nonoperative options. The most commonly described procedure is open surgical débridement of the involved tendon or peritendinous tissue with repair or augmentation of the tendon as needed. Although there are many publications describing the results of surgery in the treatment of tendinopathy, our literature search identified only four randomized, controlled studies [14, 27, 129, 144]. Two studies compared surgery to extracorporeal shock wave therapy [129, 144] and two compared surgery to exercises [14, 27].

Many studies evaluate various forms of surgery to treat Achilles tendinopathy $[92,102,109,122,139,151,191]$. The approaches vary greatly between studies based partly on the extent of abnormality. Essentially all published studies of the surgical treatment of Achilles tendinopathy are retrospective in nature without control groups. The results vary between studies and appear to correlate with the extent of tendon damage. Morberg et al. reported only a $67 \%$ satisfactory functional result at a mean followup of 6 years in a series of 64 patients who required débridement of devitalized tendon [109]. Leppilahti et al. reported $86 \%$ good to excellent results in treating patients with chronic peritendonitis, but only $69 \%$ good to excellent results when including the patients with substantial Achilles degeneration who underwent débridement of the tendon [92]. Shepsis et al. showed similar results in 54 runners who underwent surgery for chronic Achilles pain [151]. They reported satisfactory results in $87 \%$ of patients with paratendonitis and $67 \%$ in those with tendinosis.

Surgery has also been advocated for lateral epicondylitis that has failed nonoperative treatment [115]. Nirschl and Pettrone described a 97.7\% improvement rate with his open débridement procedure with $85.2 \%$ of patients returning to full activity [115]. Since then, several reports have been published describing the results of open, arthroscopic, and percutaneous procedures for the treatment of lateral epicondylitis [66, 80, 128, 176, 179]. Success rates in the $65 \%$ to $95 \%$ range have been reported, but all published reports have been retrospective or prospective case series without adequate controls. It is difficult to determine the best surgical approach for lateral epicondylitis because of the multitude of reports of different types of surgery that all seem to have moderately good results. A systematic review of surgical procedures for lateral epicondylitis reported in the Cochrane Database suggested no conclusions could be made because of the lack of controlled studies [28]. 
The results of surgical options for rotator cuff tendinopathy are also difficult to interpret. Rotator cuff tendinopathy of the shoulder is commonly believed the result of outlet impingement [113]. Accordingly, open and/ or arthroscopic acromioplasty have been the standard treatment for this condition if nonoperative measures have failed. Unless there is a partial- or full-thickness rotator cuff tear, the tendon itself is not addressed. Removing the bursa and impinging bone of the anterolateral acromion appears to provide good results in the vast majority of published trials [18, 70, 118, 169]. As mentioned earlier, the only randomized, placebo-controlled study to compare acromioplasty or supervised exercises to placebo in the treatment of shoulder impingement reported improvement in the surgery and exercise group compared to placebo [27]. No difference was seen between the surgery and exercise groups.

There is not a great deal of evidence available regarding the best treatment once the tendon is degenerating and partially torn. Cordasco et al. showed good results with acromioplasty and débridement without rotator cuff repair in the treatment of articular-sided partial-thickness tears involving less than $50 \%$ of the tendon thickness [38]. Interestingly, they did not see a progression to full-thickness tears in these patients up to 10 years after the procedure. In contrast, bursal-sided tears proved much more likely to progress to full-thickness lesions in this series. If the rotator cuff is partially torn involving more than $50 \%$ of its substance, the best available evidence supports repairing the torn tendon rather than simply débriding it and doing an acromioplasty [38, 57, 192]. However, no prospective, randomized trials have been published looking at the results of repair versus débridement of partial-thickness rotator cuff tears.

Arthroscopic or open débridement of chronic calcific tendonitis also appears a good option if patients fail nonoperative treatment [146, 156, 195]. Improvement in pain with a decrease in residual calcium deposits has been demonstrated after surgery compared with a matched cohort of patients treated nonoperatively [195]. Surgical débridement of homogeneous calcium deposits in the supraspinatus appeared more reliable than ESWT in a randomized, controlled trial [144]. This treatment can be facilitated by marking the calcific deposits preoperatively using ultrasound guidance [82, 162].

Although good results can be obtained with débridement and/or decompression of chronic tendinopathies, these procedures are not without morbidity. Failure rates can be as high as $20 \%$ to $30 \%$ with some of these procedures, and it is difficult to predict who will have continued problems after surgery. For this reason, surgery remains the last option in the treatment of most cases of tendinopathy, and other options need to be explored.

\section{Growth Factors}

Growth factors have drawn increasing interest in the field of tendon injury and repair. No FDA-approved treatments are currently available, but many of these factors facilitate healing. Increased levels of growth factors, including insulin growth factor-1, transforming growth factor-beta-1, and platelet-derived growth factor, occur after tendon injury in animal models [44, 54, 182]. In addition, several preliminary studies suggest adding exogenous growth factors to an injured tendon can enhance healing and repair $[45,81,138,177]$. For instance, the addition of cartilagederived morphogenic protein-2 to an animal tendon repair model recently reported an increase in the strength and organization of the repaired tendon $[111,189]$.

Although the application of growth factors to augment tendon repairs seems feasible, it is unclear whether there is a role for growth factors in the treatment of tendinopathy. Increased levels of transforming growth factor-betal and insulin growth factor-1 have been demonstrated in areas of tendinopathy, but this does not appear sufficient to heal the tendon injury [154]. One possible explanation is the absence of appropriate receptors or binding proteins needed for the growth factor signaling pathways [54].

One possible method of introducing an assortment of growth factors to an area of tendinopathy is through the injection of platelet rich plasma or autologous blood. Studies have reported improvement in pain compared to baseline following injection of autologous blood in the treatment of lateral epicondylitis [36, 50], medial epicondylitis [173], and patellar tendinosis [75]. No controlled studies have been published evaluating this treatment modality. One controlled study has evaluated platelet-rich plasma injections in the treatment of lateral epicondylitis [108]. In this study, twenty patients with chronic lateral epicondylitis were given either a single injection of platelet-rich plasma (15 patients) or bupivicaine (five patients). The results reported a 60\% improvement in visual analog pain scores in the treatment group at 8 months compared to a $16 \%$ improvement in the control group. Further investigation is required to determine whether the administration of blood concentrates and/or growth factors will be useful in the treatment of tendinopathy.

\section{Stem Cells}

Although no FDA-approved treatments are currently available, applying stem cell technology to the treatment of degenerative conditions of the musculoskeletal system such as tendinopathy is very appealing. In theory, pluripotent stem cells can be isolated and then delivered to an area of need such as an arthritic joint or degenerative 
tendon. Once the stem cells are in the desired location, either local signaling or the addition of exogenous factors can drive the pluripotent cells to differentiate into the needed cell line. Stem cell technology is currently being applied to the creation of tendon and ligament grafts and in enhancing graft incorporation [79, 88, 161]. Chong et al. applied bone marrow-derived stem cells to a rabbit Achilles tendon repair model [34]. They reported the addition of the stem cells in a fibrin carrier resulted in an increased modulus and improved collagen organization compared with control tendons at 3 weeks. Interestingly, no major differences were noted at later time points. This early work suggests stem cell technology may have a role in tendon grafting and repair, but whether this technology will successfully be applied to the treatment of tendinopathy remains to be seen.

\section{Discussion}

Tendinopathy is a common and often debilitating condition that can be quite difficult to treat. We performed an extensive review of the literature including 177 clinical trials and systematic reviews of the current treatment options for this condition. Our purpose was to provide a comprehensive and up-to-date review of these treatment options with recommendations based on the best level of evidence available.

As this is a review of the literature on the treatment of tendinopathy, the conclusions are limited by the volume and quality of the literature available. In many cases, there is not enough high level evidence available to support the efficacy of the treatment modality evaluated. The lack of suitable evidence in support of a treatment method does not necessarily imply that it is ineffective. Rather, there may be a lack of adequately powered studies to demonstrate its effectiveness. This review is also limited by the variability of the studies evaluated. It is often difficult to group the results from different studies even if they are evaluating the same treatment modality. Dosage, duration of treatment, length of follow-up, type of controls, and severity/duration of symptoms tend to vary from one study to the next. Larger, well-controlled, multi-center trials would be helpful in elucidating the effectiveness of the current treatment options available for tendinopathy.

The results of this review suggest traditional treatment methods, including a short course of NSAIDs and physical therapy, remain a reasonable first line of treatment. Our review suggests eccentric strengthening exercises are a good form of physical therapy while physical therapy modalities such as iontophoresis, ultrasound, phonophoresis, and low-level laser treatment lack sufficient evidence at this time. Corticosteroids provide temporary pain relief but do not appear to have any established longer-term benefit. When these modalities fail, other options should be considered. Glyceryl trinitrate patches are a good next step because they are reportedly effective in well-controlled studies and they result in minimal morbidity. ESWT is an excellent option for calcific tendinopathy of the shoulder, but more rigorous testing is required before advocating its use for other types of tendinopathy. Sclerosing polidocanol injections appear to provide pain relief if the involved tendon has documented neovascularization seen on Doppler ultrasound. Surgical débridement remains a last option for the treatment of tendinopathy because this has considerable cost and morbidity and modest success in treating chronic tendinopathy. In the future, growth factors and/or stem cells may provide benefit as they could potentially reverse the degenerative process and encourage the regeneration of healthy tendon.

\section{References}

1. Philadelphia Panel evidence-based clinical practice guidelines on selected rehabilitation interventions for shoulder pain. Phys Ther. 2001;81:1719-1730.

2. Adebajo AO, Nash P, Hazleman BL. A prospective double blind dummy placebo controlled study comparing triamcinolone hexacetonide injection with oral diclofenac $50 \mathrm{mg}$ TDS in patients with rotator cuff tendinitis. J Rheumatol. 1990;17:12071210.

3. Akgun K, Birtane M, Akarirmak U. Is local subacromial corticosteroid injection beneficial in subacromial impingement syndrome? Clin Rheumatol. 2004;23:496-500.

4. Albert JD, Meadeb J, Guggenbuhl P, Marin F, Benkalfate T, Thomazeau H, Chales G. High-energy extracorporeal shockwave therapy for calcifying tendinitis of the rotator cuff: a randomised trial. J Bone Joint Surg Br. 2007;89:335-341.

5. Alfredson H, Cook J. A treatment algorithm for managing Achilles tendinopathy: new treatment options. Br J Sports Med. 2007;41:211-216.

6. Alfredson H, Ohberg L. Sclerosing injections to areas of neovascularisation reduce pain in chronic Achilles tendinopathy: a double-blind randomised controlled trial. Knee Surg Sports Traumatol Arthrosc. 2005;13:338-344.

7. Alfredson H, Pietila T, Jonsson P, Lorentzon R. Heavy-load eccentric calf muscle training for the treatment of chronic Achilles tendinosis. Am J Sports Med. 1998;26:360-366.

8. Altay T, Gunal I, Ozturk H. Local injection treatment for lateral epicondylitis. Clin Orthop Relat Res. 2002:127-130.

9. Alvarez CM, Litchfield R, Jackowski D, Griffin S, Kirkley A. A prospective, double-blind, randomized clinical trial comparing subacromial injection of betamethasone and xylocaine to xylocaine alone in chronic rotator cuff tendinosis. Am J Sports Med. 2005;33:255-262.

10. Archambault JM, Jelinsky SA, Lake SP, Hill AA, Glaser DL, Soslowsky LJ. Rat supraspinatus tendon expresses cartilage markers with overuse. J Orthop Res. 2007;25:617-624.

11. Arroll B, Goodyear-Smith F. Corticosteroid injections for painful shoulder: a meta-analysis. Br J Gen Pract. 2005;55:224-228.

12. Assendelft WJ, Hay EM, Adshead R, Bouter LM. Corticosteroid injections for lateral epicondylitis: a systematic overview. $\mathrm{Br} J$ Gen Pract. 1996;46:209-216. 
13. Astrom M, Westlin N. No effect of piroxicam on achilles tendinopathy. A randomized study of 70 patients. Acta Orthop Scand. 1992;63:631-634.

14. Bahr R, Fossan B, Loken S, Engebretsen L. Surgical treatment compared with eccentric training for patellar tendinopathy (Jumper's Knee). A randomized, controlled trial. J Bone Joint Surg Am. 2006;88:1689-1698.

15. Bang MD, Deyle GD. Comparison of supervised exercise with and without manual physical therapy for patients with shoulder impingement syndrome. $J$ Orthop Sports Phys Ther. 2000;30:126-137.

16. Basford JR, Sheffield CG, Cieslak KR. Laser therapy: a randomized, controlled trial of the effects of low intensity Nd:YAG laser irradiation on lateral epicondylitis. Arch Phys Med Rehabil. 2000;81:1504-1510.

17. Bedi SS, Ellis W. Spontaneous rupture of the calcaneal tendon in rheumatoid arthritis after local steroid injection. Ann Rheum Dis. 1970;29:494-495.

18. Bengtsson $M$, Lunsjo $K$, Hermodsson $Y$, Nordqvist A, Abu-Zidan FM. High patient satisfaction after arthroscopic subacromial decompression for shoulder impingement: a prospective study of 50 patients. Acta Orthop. 2006;77:138-142.

19. Berrazueta JR, Losada A, Poveda J, Ochoteco A, Riestra A, Salas E, Amado JA. Successful treatment of shoulder pain syndrome due to supraspinatus tendinitis with transdermal nitroglycerin. A double blind study. Pain. 1996;66:63-67.

20. Binder A, Hodge G, Greenwood AM, Hazleman BL, Page Thomas DP. Is therapeutic ultrasound effective in treating soft tissue lesions? Br Med J (Clin Res Ed). 1985;290:512-514.

21. Bingol U, Altan L, Yurtkuran M. Low-power laser treatment for shoulder pain. Photomed Laser Surg. 2005;23:459-464.

22. Bisset L, Paungmali A, Vicenzino B, Beller E. A systematic review and meta-analysis of clinical trials on physical interventions for lateral epicondylalgia. $\mathrm{Br} J$ Sports Med. 2005;39:411-422; discussion 411-422.

23. Bjordal JM, Lopes-Martins RA, Iversen VV. A randomised, placebo controlled trial of low level laser therapy for activated Achilles tendinitis with microdialysis measurement of peritendinous prostaglandin E2 concentrations. $\mathrm{Br} J$ Sports Med. 2006;40:76-80; discussion 76-80.

24. Bjur D, Alfredson H, Forsgren S. The innervation pattern of the human Achilles tendon: studies of the normal and tendinosis tendon with markers for general and sensory innervation. Cell Tissue Res. 2005;320:201-206.

25. Blair B, Rokito AS, Cuomo F, Jarolem K, Zuckerman JD. Efficacy of injections of corticosteroids for subacromial impingement syndrome. J Bone Joint Surg Am. 1996;78:1685-1689.

26. Brosseau L, Casimiro L, Milne S, Robinson V, Shea B, Tugwell $\mathrm{P}$, Wells G. Deep transverse friction massage for treating tendinitis. Cochrane Database Syst Rev. 2002:CD003528.

27. Brox JI, Staff PH, Ljunggren AE, Brevik JI. Arthroscopic surgery compared with supervised exercises in patients with rotator cuff disease (stage II impingement syndrome). BMJ. 1993;307:899-903.

28. Buchbinder R, Green S, Bell S, Barnsley L, Smidt N, Assendelft WJ. Surgery for lateral elbow pain. Cochrane Database Syst Rev. 2002:CD003525.

29. Buchbinder R, Green SE, Youd JM, Assendelft WJ, Barnsley L, Smidt N. Systematic review of the efficacy and safety of shock wave therapy for lateral elbow pain. $J$ Rheumatol. 2006;33:1351-1363.

30. Burnham R, Gregg R, Healy P, Steadward R. The effectiveness of topical diclofenac for lateral epicondylitis. Clin J Sport Med. 1998;8:78-81.

31. Cacchio A, Paoloni M, Barile A, Don R, de Paulis F, Calvisi V, Ranavolo A, Frascarelli M, Santilli V, Spacca G. Effectiveness of radial shock-wave therapy for calcific tendinitis of the shoulder: single-blind, randomized clinical study. Phys Ther. 2006;86:672-682.

32. Chechick A, Amit Y, Israeli A, Horoszowski H. Recurrent rupture of the achilles tendon induced by corticosteroid injection. Br J Sports Med. 1982;16:89-90.

33. Chen YJ, Wang CJ, Yang KD, Kuo YR, Huang HC, Huang YT, Sun YC, Wang FS. Extracorporeal shock waves promote healing of collagenase-induced Achilles tendinitis and increase TGFbeta1 and IGF-I expression. J Orthop Res. 2004;22:854-861.

34. Chong AK, Ang AD, Goh JC, Hui JH, Lim AY, Lee EH, Lim $\mathrm{BH}$. Bone marrow-derived mesenchymal stem cells influence early tendon-healing in a rabbit achilles tendon model. $J$ Bone Joint Surg Am. 2007;89:74-81.

35. Chung B, Wiley JP. Effectiveness of extracorporeal shock wave therapy in the treatment of previously untreated lateral epicondylitis: a randomized controlled trial. Am J Sports Med. 2004;32:1660-1667.

36. Connell DA, Ali KE, Ahmad M, Lambert S, Corbett S, Curtis M. Ultrasound-guided autologous blood injection for tennis elbow. Skeletal Radiol. 2006;35:371-377.

37. Conroy DE, Hayes KW. The effect of joint mobilization as a component of comprehensive treatment for primary shoulder impingement syndrome. J Orthop Sports Phys Ther. 1998;28: $3-14$.

38. Cordasco FA, Backer M, Craig EV, Klein D, Warren RF. The partial-thickness rotator cuff tear: is acromioplasty without repair sufficient? Am J Sports Med. 2002;30:257-260.

39. Cosentino R, De Stefano R, Selvi E, Frati E, Manca S, Frediani B, Marcolongo R. Extracorporeal shock wave therapy for chronic calcific tendinitis of the shoulder: single blind study. Ann Rheum Dis. 2003;62:248-250.

40. Costa ML, Shepstone L, Donell ST, Thomas TL. Shock wave therapy for chronic Achilles tendon pain: a randomized placebocontrolled trial. Clin Orthop Relat Res. 2005;440:199-204.

41. Croisier JL, Foidart-Dessalle M, Tinant F, Crielaard JM, Forthomme B. An isokinetic eccentric programme for the management of chronic lateral epicondylar tendinopathy. $\mathrm{Br} J$ Sports Med. 2007;41:269-275.

42. D'Vaz AP, Ostor AJ, Speed CA, Jenner JR, Bradley M, Prevost AT, Hazleman BL. Pulsed low-intensity ultrasound therapy for chronic lateral epicondylitis: a randomized controlled trial. Rheumatology (Oxford). 2006;45:566-570.

43. DaCruz DJ, Geeson M, Allen MJ, Phair I. Achilles paratendonitis: an evaluation of steroid injection. $\mathrm{Br} J$ Sports Med. 1988;22:64-65.

44. Dahlgren LA, Mohammed HO, Nixon AJ. Temporal expression of growth factors and matrix molecules in healing tendon lesions. J Orthop Res. 2005;23:84-92.

45. Dahlgren LA, van der Meulen MC, Bertram JE, Starrak GS, Nixon AJ. Insulin-like growth factor-I improves cellular and molecular aspects of healing in a collagenase-induced model of flexor tendinitis. J Orthop Res. 2002;20:910-919.

46. Day BH, Govindasamy N, Patnaik R. Corticosteroid injections in the treatment of tennis elbow. Practitioner. 1978;220:459462.

47. Downing DS, Weinstein A. Ultrasound therapy of subacromial bursitis. A double blind trial. Phys Ther. 1986;66:194-199.

48. Dreiser RL, Ditisheim A, Charlot J, Lopez A. A double blind, placebo controlled study of niflumic acid gel in the treatment of acute tendinitis. Eur J Rheumatol Inflamm. 1991;11:38-45.

49. Ebenbichler GR, Erdogmus CB, Resch KL, Funovics MA, Kainberger F, Barisani G, Aringer M, Nicolakis P, Wiesinger GF, Baghestanian M, Preisinger E, Fialka-Moser V. Ultrasound therapy for calcific tendinitis of the shoulder. $N$ Engl J Med. 1999;340:1533-1538. 
50. Edwards SG, Calandruccio JH. Autologous blood injections for refractory lateral epicondylitis. $J$ Hand Surg [Am]. 2003;28:272-278.

51. Ellis R, Hing W, Reid D. Iliotibial band friction syndrome-a systematic review. Man Ther. 2007;12:200-208.

52. England S, Farrell AJ, Coppock JS, Struthers G, Bacon PA. Low power laser therapy of shoulder tendonitis. Scand J Rheumatol. 1989;18:427-431.

53. Fahlstrom M, Jonsson P, Lorentzon R, Alfredson H. Chronic Achilles tendon pain treated with eccentric calf-muscle training. Knee Surg Sports Traumatol Arthrosc. 2003;11:327-333.

54. Fenwick SA, Curry V, Harrall RL, Hazleman BL, Hackney R, Riley GP. Expression of transforming growth factor-beta isoforms and their receptors in chronic tendinosis. $J$ Anat. 2001;199:231-240.

55. Ford LT, DeBender J. Tendon rupture after local steroid injection. South Med J. 1979;72:827-830.

56. Frohm A, Saartok T, Halvorsen K, Renstrom P. Eccentric treatment for patellar tendinopathy: a prospective randomised short-term pilot study of two rehabilitation protocols. $\mathrm{Br} J$ Sports Med. 2007;41:e7.

57. Fukuda H, Hamada K, Nakajima T, Yamada N, Tomonaga A, Goto M. Partial-thickness tears of the rotator cuff. A clinicopathological review based on 66 surgically verified cases. Int Orthop. 1996;20:257-265.

58. Galeazzi M, Marcolongo R. A placebo-controlled study of the efficacy and tolerability of a nonsteroidal anti-inflammatory drug, DHEP plaster, in inflammatory peri- and extra-articular rheumatological diseases. Drugs Exp Clin Res. 1993;19:107115.

59. Gerdesmeyer L, Wagenpfeil S, Haake M, Maier M, Loew M, Wortler K, Lampe R, Seil R, Handle G, Gassel S, Rompe JD. Extracorporeal shock wave therapy for the treatment of chronic calcifying tendonitis of the rotator cuff: a randomized controlled trial. JAMA. 2003;290:2573-2580.

60. Gill SS, Gelbke MK, Mattson SL, Anderson MW, Hurwitz SR. Fluoroscopically guided low-volume peritendinous corticosteroid injection for Achilles tendinopathy. A safety study. J Bone Joint Surg Am. 2004;86-A:802-806.

61. Ginsberg F, Famaey JP. Double-blind, randomized crossover study of the percutaneous efficacy and tolerability of a topical indomethacin spray versus placebo in the treatment of tendinitis. J Int Med Res. 1991;19:131-136.

62. Giombini A, Di Cesare A, Casciello G, Sorrenti D, Dragoni S, Gabriele P. Hyperthermia at $434 \mathrm{MHz}$ in the treatment of overuse sport tendinopathies: a randomised controlled clinical trial. Int J Sports Med. 2002;23:207-211.

63. Giombini A, Di Cesare A, Safran MR, Ciatti R, Maffulli N. Short-term effectiveness of hyperthermia for supraspinatus tendinopathy in athletes: a short-term randomized controlled study. Am J Sports Med. 2006;34:1247-1253.

64. Green S, Buchbinder R, Barnsley L, Hall S, White M, Smidt N, Assendelft W. Non-steroidal anti-inflammatory drugs (NSAIDs) for treating lateral elbow pain in adults. Cochrane Database Syst Rev. 2002:CD003686.

65. Green S, Buchbinder R, Hetrick S. Physiotherapy interventions for shoulder pain. Cochrane Database Syst Rev. 2003: CD004258.

66. Grundberg AB, Dobson JF. Percutaneous release of the common extensor origin for tennis elbow. Clin Orthop Relat Res. 2000:137-140.

67. Haake M, Deike B, Thon A, Schmitt J. Exact focusing of extracorporeal shock wave therapy for calcifying tendinopathy. Clin Orthop Relat Res. 2002:323-331.

68. Haake M, Konig IR, Decker T, Riedel C, Buch M, Muller HH. Extracorporeal shock wave therapy in the treatment of lateral epicondylitis: a randomized multicenter trial. J Bone Joint Surg Am. 2002;84-A:1982-1991.

69. Haker E, Lundeberg T. Laser treatment applied to acupuncture points in lateral humeral epicondylalgia. A double-blind study. Pain. 1990;43:243-247.

70. Hawkins RJ, Brock RM, Abrams JS, Hobeika P. Acromioplasty for impingement with an intact rotator cuff. J Bone Joint Surg Br. 1988;70:795-797.

71. Hay EM, Paterson SM, Lewis M, Hosie G, Croft P. Pragmatic randomised controlled trial of local corticosteroid injection and naproxen for treatment of lateral epicondylitis of elbow in primary care. Bmj. 1999;319:964-968.

72. Hoksrud A, Ohberg L, Alfredson H, Bahr R. Ultrasound-guided sclerosis of neovessels in painful chronic patellar tendinopathy: a randomized controlled trial. Am J Sports Med. 2006;34:17381746.

73. Hollingworth GR, Ellis RM, Hattersley TS. Comparison of injection techniques for shoulder pain: results of a double blind, randomised study. Br Med J (Clin Res Ed). 1983;287:1339-1341.

74. Jakobeit C, Winiarski B, Jakobeit S, Welp L, Spelsberg G. Ultrasound-guided, high-energy extracorporeal - shock-wave treatment of symptomatic calcareous tendinopathy of the shoulder. ANZ J Surg. 2002;72:496-500.

75. James SL, Ali K, Pocock C, Robertson C, Walter J, Bell J, Connell D. Ultrasound guided dry needling and autologous blood injection for patellar tendinosis. $\mathrm{Br} \mathrm{J}$ Sports Med. 2007;41:518-521; discussion 522.

76. Jones GC, Corps AN, Pennington CJ, Clark IM, Edwards DR, Bradley MM, Hazleman BL, Riley GP. Expression profiling of metalloproteinases and tissue inhibitors of metalloproteinases in normal and degenerate human achilles tendon. Arthritis Rheum. 2006;54:832-842.

77. Jones JG. Achilles tendon rupture following steroid injection. J Bone Joint Surg Am. 1985;67:170.

78. Jonsson P, Alfredson H. Superior results with eccentric compared to concentric quadriceps training in patients with jumper's knee: a prospective randomised study. $\mathrm{Br} J$ Sports Med. 2005;39:847-850.

79. Juncosa-Melvin N, Boivin GP, Gooch C, Galloway MT, West JR, Dunn MG, Butler DL. The effect of autologous mesenchymal stem cells on the biomechanics and histology of gelcollagen sponge constructs used for rabbit patellar tendon repair. Tissue Eng. 2006;12:369-379.

80. Kaleli T, Ozturk C, Temiz A, Tirelioglu O. Surgical treatment of tennis elbow: percutaneous release of the common extensor origin. Acta Orthop Belg. 2004;70:131-133.

81. Kashiwagi K, Mochizuki Y, Yasunaga Y, Ishida O, Deie M, Ochi M. Effects of transforming growth factor-beta 1 on the early stages of healing of the Achilles tendon in a rat model. Scand J Plast Reconstr Surg Hand Surg. 2004;38:193-197.

82. Kayser R, Hampf S, Seeber E, Heyde CE. Value of preoperative ultrasound marking of calcium deposits in patients who require surgical treatment of calcific tendinitis of the shoulder. Arthroscopy. 2007;23:43-50.

83. Khan KM, Cook JL, Bonar F, Harcourt P, Astrom M. Histopathology of common tendinopathies. Update and implications for clinical management. Sports Med. 1999;27:393-408.

84. Klaiman MD, Shrader JA, Danoff JV, Hicks JE, Pesce WJ, Ferland J. Phonophoresis versus ultrasound in the treatment of common musculoskeletal conditions. Med Sci Sports Exerc. 1998;30:1349-1355.

85. Kleinman M, Gross AE. Achilles tendon rupture following steroid injection. Report of three cases. J Bone Joint Surg Am. 1983;65:1345-1347.

86. Koester MC, Dunn WR, Kuhn JE, Spindler KP. The efficacy of subacromial corticosteroid injection in the treatment of rotator 
cuff disease: A systematic review. J Am Acad Orthop Surg. 2007;15:3-11.

87. Krasheninnikoff M, Ellitsgaard N, Rogvi-Hansen B, Zeuthen A, Harder K, Larsen R, Gaardbo H. No effect of low power laser in lateral epicondylitis. Scand J Rheumatol. 1994;23:260-263.

88. Kryger GS, Chong AK, Costa M, Pham H, Bates SJ, Chang J. A comparison of tenocytes and mesenchymal stem cells for use in flexor tendon tissue engineering. $J$ Hand Surg [Am]. 2007;32:597-605.

89. Labelle H, Guibert R. Efficacy of diclofenac in lateral epicondylitis of the elbow also treated with immobilization. The University of Montreal Orthopaedic Research Group. Arch Fam Med. 1997;6:257-262.

90. Lam LK, Cheing GL. Effects of 904-nm low-level laser therapy in the management of lateral epicondylitis: a randomized controlled trial. Photomed Laser Surg. 2007;25:65-71.

91. Lebrun CM. Low-dose extracorporeal shock wave therapy for previously untreated lateral epicondylitis. Clin J Sport Med. 2005; 15:401-402.

92. Leppilahti J, Orava S, Karpakka J, Takala T. Overuse injuries of the Achilles tendon. Ann Chir Gynaecol. 1991;80:202-207.

93. Lian O, Scott A, Engebretsen L, Bahr R, Duronio V, Khan K. Excessive apoptosis in patellar tendinopathy in athletes. Am J Sports Med. 2007;35:605-611.

94. Lind B, Ohberg L, Alfredson H. Sclerosing polidocanol injections in mid-portion Achilles tendinosis: remaining good clinical results and decreased tendon thickness at 2-year follow-up. Knee Surg Sports Traumatol Arthrosc. 2006;14:1327-1332.

95. Ljung BO, Alfredson H, Forsgren S. Neurokinin 1-receptors and sensory neuropeptides in tendon insertions at the medial and lateral epicondyles of the humerus. Studies on tennis elbow and medial epicondylalgia. J Orthop Res. 2004;22:321-327.

96. Ljung BO, Forsgren S, Friden J. Substance P and calcitonin gene-related peptide expression at the extensor carpi radialis brevis muscle origin: implications for the etiology of tennis elbow. J Orthop Res. 1999;17:554-559.

97. Ljung BO, Forsgren S, Friden J. Sympathetic and sensory innervations are heterogeneously distributed in relation to the blood vessels at the extensor carpi radialis brevis muscle origin of man. Cells Tissues Organs. 1999;165:45-54.

98. Loew M, Daecke W, Kusnierczak D, Rahmanzadeh M, Ewerbeck V. Shock-wave therapy is effective for chronic calcifying tendinitis of the shoulder. J Bone Joint Surg Br. 1999;81: 863-867.

99. Longo UG, Franceschi F, Ruzzini L, Rabitti C, Morini S, Maffulli N, Forriol F, Denaro V. Light microscopic histology of supraspinatus tendon ruptures. Knee Surg Sports Traumatol Arthrosc. 2007;15:1390-1394.

100. Lopez JM. Treatment of acute tendinitis and bursitis with fentiazac-a double-blind comparison with placebo. Clin Ther. 1982;5:79-84.

101. Lundeberg T, Haker E, Thomas M. Effect of laser versus placebo in tennis elbow. Scand J Rehabil Med. 1987;19:135-138.

102. Maffulli N, Testa V, Capasso G, Oliva F, Sullo A, Benazzo F, Regine R, King JB. Surgery for chronic Achilles tendinopathy yields worse results in nonathletic patients. Clin J Sport Med. 2006; 16:123-128.

103. Mafi N, Lorentzon R, Alfredson H. Superior short-term results with eccentric calf muscle training compared to concentric training in a randomized prospective multicenter study on patients with chronic Achilles tendinosis. Knee Surg Sports Traumatol Arthrosc. 2001;9:42-47.

104. Martinez-Silvestrini JA, Newcomer KL, Gay RE, Schaefer MP, Kortebein P, Arendt KW. Chronic lateral epicondylitis: comparative effectiveness of a home exercise program including stretching alone versus stretching supplemented with eccentric or concentric strengthening. J Hand Ther. 2005;18:411-419, quiz 420.

105. Mazieres B, Rouanet S, Guillon Y, Scarsi C, Reiner V. Topical ketoprofen patch in the treatment of tendinitis: a randomized, double blind, placebo controlled study. $J$ Rheumatol. 2005;32:1563-1570.

106. McLauchlan GJ, Handoll HH. Interventions for treating acute and chronic Achilles tendinitis. Cochrane Database Syst Rev. 2001:CD000232.

107. Mena HR, Lomen PL, Turner LF, Lamborn KR, Brinn EL. Treatment of acute shoulder syndrome with flurbiprofen. Am J Med. 1986;80:141-144.

108. Mishra A, Pavelko T. Treatment of chronic elbow tendinosis with buffered platelet-rich plasma. Am J Sports Med. 2006;34:1774-1778.

109. Morberg P, Jerre R, Sward L, Karlsson J. Long-term results after surgical management of partial Achilles tendon ruptures. Scand J Med Sci Sports. 1997;7:299-303.

110. Moretti B, Garofalo R, Genco S, Patella V, Mouhsine E. Medium-energy shock wave therapy in the treatment of rotator cuff calcifying tendinitis. Knee Surg Sports Traumatol Arthrosc. 2005;13:405-410.

111. Murray DH, Kubiak EN, Jazrawi LM, Araghi A, Kummer F, Loebenberg MI, Zuckerman JD. The effect of cartilage-derived morphogenetic protein 2 on initial healing of a rotator cuff defect in a rat model. J Shoulder Elbow Surg. 2007;16:251-254.

112. Murrell GA, Szabo C, Hannafin JA, Jang D, Dolan MM, Deng $\mathrm{XH}$, Murrell DF, Warren RF. Modulation of tendon healing by nitric oxide. Inflamm Res. 1997;46:19-27.

113. Neer CS, 2nd. Anterior acromioplasty for the chronic impingement syndrome in the shoulder: a preliminary report. J Bone Joint Surg Am. 1972;54:41-50.

114. Newcomer KL, Laskowski ER, Idank DM, McLean TJ, Egan KS. Corticosteroid injection in early treatment of lateral epicondylitis. Clin J Sport Med. 2001;11:214-222.

115. Nirschl RP, Pettrone FA. Tennis elbow. The surgical treatment of lateral epicondylitis. J Bone Joint Surg Am. 1979;61:832839.

116. Nirschl RP, Rodin DM, Ochiai DH, Maartmann-Moe C. Iontophoretic administration of dexamethasone sodium phosphate for acute epicondylitis. A randomized, double-blinded, placebocontrolled study. Am J Sports Med. 2003;31:189-195.

117. Norregaard J, Larsen CC, Bieler T, Langberg H. Eccentric exercise in treatment of Achilles tendinopathy. Scand J Med Sci Sports. 2007;17:133-138.

118. Nutton RW, McBirnie JM, Phillips C. Treatment of chronic rotator-cuff impingement by arthroscopic subacromial decompression. J Bone Joint Surg Br. 1997;79:73-76.

119. Ohberg L, Alfredson H. Ultrasound guided sclerosis of neovessels in painful chronic Achilles tendinosis: pilot study of a new treatment. Br J Sports Med. 2002;36:173-175; discussion 176-177.

120. Ohberg L, Lorentzon R, Alfredson H. Eccentric training in patients with chronic Achilles tendinosis: normalised tendon structure and decreased thickness at follow up. Br J Sports Med. 2004;38:8-11; discussion 11.

121. Ohtori S, Inoue G, Mannoji C, Saisu T, Takahashi K, Mitsuhashi S, Wada Y, Takahashi K, Yamagata M, Moriya H. Shock wave application to rat skin induces degeneration and reinnervation of sensory nerve fibres. Neurosci Lett. 2001;315:57-60.

122. Paavola M, Kannus P, Orava S, Pasanen M, Jarvinen M. Surgical treatment for chronic Achilles tendinopathy: a prospective seven month follow up study. Br J Sports Med. 2002;36:178182.

123. Pan PJ, Chou CL, Chiou HJ, Ma HL, Lee HC, Chan RC. Extracorporeal shock wave therapy for chronic calcific tendinitis 
of the shoulders: a functional and sonographic study. Arch Phys Med Rehabil. 2003;84:988-993.

124. Paoloni JA, Appleyard RC, Nelson J, Murrell GA. Topical nitric oxide application in the treatment of chronic extensor tendinosis at the elbow: a randomized, double-blinded, placebo-controlled clinical trial. Am J Sports Med. 2003;31:915-920.

125. Paoloni JA, Appleyard RC, Nelson J, Murrell GA. Topical glyceryl trinitrate treatment of chronic noninsertional achilles tendinopathy. A randomized, double-blind, placebo-controlled trial. J Bone Joint Surg Am. 2004;86-A:916-922.

126. Paoloni JA, Appleyard RC, Nelson J, Murrell GA. Topical glyceryl trinitrate application in the treatment of chronic supraspinatus tendinopathy: a randomized, double-blinded, placebo-controlled clinical trial. Am J Sports Med. 2005;33:806813.

127. Paoloni JA, Murrell GA. Three-year followup study of topical glyceryl trinitrate treatment of chronic noninsertional Achilles tendinopathy. Foot Ankle Int. 2007;28:1064-1068.

128. Peart RE, Strickler SS, Schweitzer KM Jr. Lateral epicondylitis: a comparative study of open and arthroscopic lateral release. Am J Orthop. 2004;33:565-567.

129. Peers KH, Lysens RJ, Brys P, Bellemans J. Cross-sectional outcome analysis of athletes with chronic patellar tendinopathy treated surgically and by extracorporeal shock wave therapy. Clin J Sport Med. 2003;13:79-83.

130. Perlick L, Luring C, Bathis H, Perlick C, Kraft C, Diedrich O. Efficacy of extracorporal shock-wave treatment for calcific tendinitis of the shoulder: experimental and clinical results. J Orthop Sci. 2003;8:777-783.

131. Peters J, Luboldt W, Schwarz W, Jacobi V, Herzog C, Vogl TJ. Extracorporeal shock wave therapy in calcific tendinitis of the shoulder. Skeletal Radiol. 2004;33:712-718.

132. Petersen W, Welp R, Rosenbaum D. Chronic Achilles tendinopathy: a prospective randomized study comparing the therapeutic effect of eccentric training, the AirHeel brace, and a combination of both. Am J Sports Med. 2007;35:1659-1667.

133. Petri M, Dobrow R, Neiman R, Whiting-O'Keefe Q, Seaman WE. Randomized, double-blind, placebo-controlled study of the treatment of the painful shoulder. Arthritis Rheum. 1987;30:1040-1045.

134. Petri M, Hufman SL, Waser G, Cui H, Snabes MC, Verburg KM. Celecoxib effectively treats patients with acute shoulder tendinitis/bursitis. J Rheumatol. 2004;31:1614-1620.

135. Pettrone FA, McCall BR. Extracorporeal shock wave therapy without local anesthesia for chronic lateral epicondylitis. J Bone Joint Surg Am. 2005;87:1297-1304.

136. Pleiner J, Crevenna R, Langenberger H, Keilani M, Nuhr M, Kainberger F, Wolzt M, Wiesinger G, Quittan M. Extracorporeal shockwave treatment is effective in calcific tendonitis of the shoulder. A randomized controlled trial. Wien Klin Wochenschr. 2004; 116:536-541.

137. Robertson VJ, Baker KG. A review of therapeutic ultrasound: effectiveness studies. Phys Ther. 2001;81:1339-1350.

138. Rodeo SA, Potter HG, Kawamura S, Turner AS, Kim HJ, Atkinson BL. Biologic augmentation of rotator cuff tendonhealing with use of a mixture of osteoinductive growth factors. J Bone Joint Surg Am. 2007;89:2485-2497.

139. Rolf C, Movin T. Etiology, histopathology, and outcome of surgery in achillodynia. Foot Ankle Int. 1997;18:565-569.

140. Rompe JD, Burger R, Hopf C, Eysel P. Shoulder function after extracorporal shock wave therapy for calcific tendinitis. J Shoulder Elbow Surg. 1998;7:505-509.

141. Rompe JD, Furia J, Maffulli N. Eccentric loading compared with shock wave treatment for chronic insertional achilles tendinopathy. A randomized, controlled trial. J Bone Joint Surg Am. 2008;90:52-61.
142. Rompe JD, Maffulli N. Repetitive shock wave therapy for lateral elbow tendinopathy (tennis elbow): a systematic and qualitative analysis. Br Med Bull. 2007;83:355-378.

143. Rompe JD, Nafe B, Furia JP, Maffulli N. Eccentric loading, shock-wave treatment, or a wait-and-see policy for tendinopathy of the main body of tendo Achillis: a randomized controlled trial. Am J Sports Med. 2007;35:374-383.

144. Rompe JD, Zoellner J, Nafe B. Shock wave therapy versus conventional surgery in the treatment of calcifying tendinitis of the shoulder. Clin Orthop Relat Res. 2001:72-82.

145. Roos EM, Engstrom M, Lagerquist A, Soderberg B. Clinical improvement after 6 weeks of eccentric exercise in patients with mid-portion Achilles tendinopathy - a randomized trial with 1-year follow-up. Scand J Med Sci Sports. 2004;14:286-295.

146. Rubenthaler F, Ludwig J, Wiese M, Wittenberg RH. Prospective randomized surgical treatments for calcifying tendinopathy. Clin Orthop Relat Res. 2003:278-284.

147. Runeson L, Haker E. Iontophoresis with cortisone in the treatment of lateral epicondylalgia (tennis elbow)-a double-blind study. Scand J Med Sci Sports. 2002;12:136-142.

148. Russell AL. Piroxicam $0.5 \%$ topical gel compared to placebo in the treatment of acute soft tissue injuries: a double-blind study comparing efficacy and safety. Clin Invest Med. 1991;14:35-43.

149. Saartok T, Eriksson E. Randomized trial of oral naproxen or local injection of betamethasone in lateral epicondylitis of the humerus. Orthopedics. 1986;9:191-194.

150. Sabeti-Aschraf M, Dorotka R, Goll A, Trieb K. Extracorporeal shock wave therapy in the treatment of calcific tendinitis of the rotator cuff. Am J Sports Med. 2005;33:1365-1368.

151. Schepsis AA, Wagner C, Leach RE. Surgical management of Achilles tendon overuse injuries. A long-term follow-up study. Am J Sports Med. 1994;22:611-619.

152. Schmitt J, Haake M, Tosch A, Hildebrand R, Deike B, Griss P. Low-energy extracorporeal shock-wave treatment (ESWT) for tendinitis of the supraspinatus. A prospective, randomised study. J Bone Joint Surg Br. 2001;83:873-876.

153. Schorn D. Tenoxicam in soft-tissue rheumatism. S Afr Med J. 1986;69:301-303.

154. Scott A, Cook JL, Hart DA, Walker DC, Duronio V, Khan KM. Tenocyte responses to mechanical loading in vivo: a role for local insulin-like growth factor 1 signaling in early tendinosis in rats. Arthritis Rheum. 2007;56:871-881.

155. Scott A, Khan KM, Duronio V. IGF-I activates PKB and prevents anoxic apoptosis in Achilles tendon cells. J Orthop Res. 2005;23:1219-1225.

156. Seil R, Litzenburger H, Kohn D, Rupp S. Arthroscopic treatment of chronically painful calcifying tendinitis of the supraspinatus tendon. Arthroscopy. 2006;22:521-527.

157. Shalabi A, Kristoffersen-Wilberg M, Svensson L, Aspelin P, Movin T. Eccentric training of the gastrocnemius-soleus complex in chronic Achilles tendinopathy results in decreased tendon volume and intratendinous signal as evaluated by MRI. Am J Sports Med. 2004;32:1286-1296.

158. Silbernagel KG, Thomee R, Thomee P, Karlsson J. Eccentric overload training for patients with chronic Achilles tendon paina randomised controlled study with reliability testing of the evaluation methods. Scand J Med Sci Sports. 2001;11:197-206.

159. Smidt N, Assendelft WJ, van der Windt DA, Hay EM, Buchbinder R, Bouter LM. Corticosteroid injections for lateral epicondylitis: a systematic review. Pain. 2002;96:23-40.

160. Smidt N, van der Windt DA, Assendelft WJ, Deville WL, Korthals-de Bos IB, Bouter LM. Corticosteroid injections, physiotherapy, or a wait-and-see policy for lateral epicondylitis: a randomised controlled trial. Lancet. 2002;359:657-662.

161. Soon MY, Hassan A, Hui JH, Goh JC, Lee EH. An analysis of soft tissue allograft anterior cruciate ligament reconstruction in a 
rabbit model: a short-term study of the use of mesenchymal stem cells to enhance tendon osteointegration. Am J Sports Med. 2007;35:962-971.

162. Sorensen L, Teichert G, Skjodt T, Dichmann OL. Preoperative ultrasonographic-guided marking of calcium deposits in the rotator cuff facilitates localization during arthroscopic surgery. Arthroscopy. 2004;20:103-104.

163. Soslowsky LJ, Thomopoulos S, Tun S, Flanagan CL, Keefer CC, Mastaw J, Carpenter JE. Neer Award 1999. Overuse activity injures the supraspinatus tendon in an animal model: a histologic and biomechanical study. J Shoulder Elbow Surg. 2000;9:79-84

164. Spacca G, Cacchio A, Forgacs A, Monteforte P, Rovetta G. Analgesic efficacy of a lecithin-vehiculated diclofenac epolamine gel in shoulder periarthritis and lateral epicondylitis: a placebo-controlled, multicenter, randomized, double-blind clinical trial. Drugs Exp Clin Res. 2005;31:147-154.

165. Speed CA, Nichols D, Richards C, Humphreys H, Wies JT, Burnet S, Hazleman BL. Extracorporeal shock wave therapy for lateral epicondylitis-a double blind randomised controlled trial. J Orthop Res. 2002;20:895-898.

166. Speed CA, Richards C, Nichols D, Burnet S, Wies JT, Humphreys H, Hazleman BL. Extracorporeal shock-wave therapy for tendonitis of the rotator cuff. A double-blind, randomised, controlled trial. $J$ Bone Joint Surg Br. 2002;84:509-512.

167. Stasinopoulos D, Stasinopoulos I. Comparison of effects of exercise programme, pulsed ultrasound and transverse friction in the treatment of chronic patellar tendinopathy. Clin Rehabil. 2004; 18:347-352.

168. Stasinopoulos DI, Johnson MI. Effectiveness of low-level laser therapy for lateral elbow tendinopathy. Photomed Laser Surg. 2005;23:425-430.

169. Stephens SR, Warren RF, Payne LZ, Wickiewicz TL, Altchek DW. Arthroscopic acromioplasty: a 6- to 10-year follow-up. Arthroscopy. 1998;14:382-388.

170. Stergioulas A. Effects of low-level laser and plyometric exercises in the treatment of lateral epicondylitis. Photomed Laser Surg. 2007;25:205-213.

171. Stergioulas A, Stergioula M, Aarskog R, Lopes-Martins RA, Bjordal JM. Effects of low-level laser therapy and eccentric exercises in the treatment of recreational athletes with chronic achilles tendinopathy. Am J Sports Med. 2008.

172. Stratz T, Farber L, Muller W. Local treatment of tendinopathies: a comparison between tropisetron and depot corticosteroids combined with local anesthetics. Scand $J$ Rheumatol. 2002;31:366-370.

173. Suresh SP, Ali KE, Jones H, Connell DA. Medial epicondylitis: is ultrasound guided autologous blood injection an effective treatment? Br J Sports Med. 2006;40:935-939; discussion 939.

174. Szomor ZL, Appleyard RC, Murrell GA. Overexpression of nitric oxide synthases in tendon overuse. J Orthop Res. 2006;24:80-86.

175. Takahashi N, Ohtori S, Saisu T, Moriya H, Wada Y. Second application of low-energy shock waves has a cumulative effect on free nerve endings. Clin Orthop Relat Res. 2006;443:315319.

176. Tasto JP, Cummings J, Medlock V, Hardesty R, Amiel D. Microtenotomy using a radiofrequency probe to treat lateral epicondylitis. Arthroscopy. 2005;21:851-860.

177. Thomopoulos S, Zaegel M, Das R, Harwood FL, Silva MJ, Amiel D, Sakiyama-Elbert S, Gelberman RH. PDGF-BB released in tendon repair using a novel delivery system promotes cell proliferation and collagen remodeling. J Orthop Res. 2007;25:1358-1368.
178. Thorling J, Linden B, Berg R, Sandahl A. A double-blind comparison of naproxen gel and placebo in the treatment of soft tissue injuries. Curr Med Res Opin. 1990;12:242-248.

179. Thornton SJ, Rogers JR, Prickett WD, Dunn WR, Allen AA, Hannafin JA. Treatment of recalcitrant lateral epicondylitis with suture anchor repair. Am J Sports Med. 2005;33:1558-1564.

180. Tonks JH, Pai SK, Murali SR. Steroid injection therapy is the best conservative treatment for lateral epicondylitis: a prospective randomised controlled trial. Int J Clin Pract. 2007;61:240 246.

181. Trudel D, Duley J, Zastrow I, Kerr EW, Davidson R, MacDermid JC. Rehabilitation for patients with lateral epicondylitis: a systematic review. J Hand Ther. 2004;17:243-266.

182. Tsubone T, Moran SL, Amadio PC, Zhao C, An KN. Expression of growth factors in canine flexor tendon after laceration in vivo. Ann Plast Surg. 2004;53:393-397.

183. van der Windt DA, van der Heijden GJ, van den Berg SG, ter Riet G, de Winter AF, Bouter LM. Ultrasound therapy for musculoskeletal disorders: a systematic review. Pain. 1999;81:257-271.

184. Vasseljen O, Jr., Hoeg N, Kjeldstad B, Johnsson A, Larsen S. Low level laser versus placebo in the treatment of tennis elbow. Scand J Rehabil Med. 1992;24:37-42.

185. Vecchini L, Grossi E. Ionization with diclofenac sodium in rheumatic disorders: a double-blind placebo-controlled trial. J Int Med Res. 1984;12:346-350.

186. Vecchio P, Cave M, King V, Adebajo AO, Smith M, Hazleman BL. A double-blind study of the effectiveness of low level laser treatment of rotator cuff tendinitis. $\mathrm{Br} J$ Rheumatol. 1993;32:740-742.

187. Vecchio PC, Hazleman BL, King RH. A double-blind trial comparing subacromial methylprednisolone and lignocaine in acute rotator cuff tendinitis. Br J Rheumatol. 1993;32:743-745.

188. Verhaar JA, Walenkamp GH, van Mameren H, Kester AD, van der Linden AJ. Local corticosteroid injection versus Cyriax-type physiotherapy for tennis elbow. J Bone Joint Surg Br. 1996;78:128-132.

189. Virchenko O, Fahlgren A, Skoglund B, Aspenberg P. CDMP-2 injection improves early tendon healing in a rabbit model for surgical repair. Scand J Med Sci Sports. 2005;15:260-264.

190. Visnes H, Hoksrud A, Cook J, Bahr R. No effect of eccentric training on jumper's knee in volleyball players during the competitive season: a randomized clinical trial. Clin J Sport Med. 2005;15:227-234.

191. Wagner E, Gould JS, Kneidel M, Fleisig GS, Fowler R. Technique and results of Achilles tendon detachment and reconstruction for insertional Achilles tendinosis. Foot Ankle Int. 2006;27:677-684.

192. Weber SC. Arthroscopic debridement and acromioplasty versus mini-open repair in the treatment of significant partial-thickness rotator cuff tears. Arthroscopy. 1999;15:126-131.

193. White RH, Paull DM, Fleming KW. Rotator cuff tendinitis: comparison of subacromial injection of a long acting corticosteroid versus oral indomethacin therapy. $J$ Rheumatol. 1986;13:608-613.

194. Withrington RH, Girgis FL, Seifert MH. A placebo-controlled trial of steroid injections in the treatment of supraspinatus tendonitis. Scand J Rheumatol. 1985;14:76-78.

195. Wittenberg RH, Rubenthaler F, Wolk T, Ludwig J, Willburger RE, Steffen R. Surgical or conservative treatment for chronic rotator cuff calcifying tendinitis-a matched-pair analysis of 100 patients. Arch Orthop Trauma Surg. 2001;121:56-59.

196. Wober W, Rahlfs VW, Buchl N, Grassle A, Macciocchi A. Comparative efficacy and safety of the non-steroidal antiinflammatory drugs nimesulide and diclofenac in patients with 
acute subdeltoid bursitis and bicipital tendinitis. Int J Clin Pract. 1998;52:169-175.

197. Woodley BL, Newsham-West RJ, Baxter GD. Chronic tendinopathy: effectiveness of eccentric exercise. Br J Sports Med. 2007;41:188-198; discussion 199.

198. Yuan J, Murrell GA, Wei AQ, Appleyard RC, Del Soldato P, Wang MX. Addition of nitric oxide via nitroflurbiprofen enhances the material properties of early healing of young rat Achilles tendons. Inflamm Res. 2003;52:230-237.

199. Yuan J, Murrell GA, Wei AQ, Wang MX. Apoptosis in rotator cuff tendonopathy. J Orthop Res. 2002;20:1372-1379.

200. Zeisig E, Ohberg L, Alfredson H. Sclerosing polidocanol injections in chronic painful tennis elbow-promising results in a pilot study. Knee Surg Sports Traumatol Arthrosc. 2006;14:1218-1224. 